International Journal of Instruction e-ISSN: 1308-1470 • www.e-iji.net

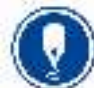

April 2021 • Vol.14, No.2

p-ISSN: 1694-609X

pp. 935-952

Article submission code 20200518102256

Received: 18/05/2020

Revision: 05/11/2020
Accepted: 27/11/2020

OnlineFirst: 13/03/2021

\title{
Accompanying Persons with Disabilities at University: Skills Development among Volunteers
}

Tatiana Lukovenko

Pacific National University, Khabarovsk, Russia,009854@ pnи.edu.ru

Natalia Kalugina

Pacific National University, Khabarovsk, Russia,natalikhbru@mail.ru

\section{Nikolay Sorokin}

Pacific National University, Khabarovsk, Russia, 004040@ pпи.edu.ru

\section{Oleg Bulavenko}

Federal State Budgetary Educational Establishment of Higher Education "Amur Humanitarian-Pedagogical State University", Russia, o-bul@yandex.ru

Caring for people with disabilities and their social adaptation around the world is effectively carried out with the help of volunteer organizations and social workers. Training of volunteers is effective, which is critical both for advocating for people with disabilities and for motivating and expanding the volunteer movement. The study's objective is to analyse the effectiveness of a training program that will help volunteers develop skills for the accompaniment of disabled students. The article analyses the effectiveness of volunteer movement conducted at the Regional Resource and Education Centre for Disabled People and People with Special Needs, Pacific National University (Russia, Khabarovsk). From October 22 to November 28, 2019, a resource-based education centre for people with disabilities has conducted a survey to investigate issues of inclusive volunteering among 78 participants (75 students, 3 university workers) with special needs from 8 universities of the Far East Federal District (FEFD). The level of volunteers' selfreported perceptions towards persons with various disabilities increased from average to above average and high. Moreover, the knowledge on how to interact with disabled people has also improved. The results of the study describe the students' interest in various types of volunteer activities. Besides, the main directions for the formation of skills needed, to accompany people with reduced capabilities are built. The comparative representation of program units provides a better understanding of the existing problems and allows effective solutions.

Keywords: competencies development, health limitations; higher education, program, students with disabilities, volunteers

Citation: Lukoyenko, T., Kalugina, N., Sorokin, N., \& Bulavenko, O. (2021). Accompanying Persons with Disabilities at University: Skills Development among Volunteers. International Journal of Instruction, 14(2), 935-952. https://doi.org/10.29333/iji.2021.14253a 


\section{INTRODUCTION}

The current humanization of society manifests in all spheres of life: economic, political, social. One of the examples of humanity is a change in the attitude towards the most vulnerable part of the community - people with disabilities and special needs (Rochester et al., 2016; Yanay-Ventura, 2019). The United Nations (UN) considered and presented several documents aimed at protecting the rights of persons with various disabilities, recognizing their right to education and a barrier-free environment. Among these documents are Convention on the Rights of Persons with Disabilities, World Conference on Education for All, Declaration on the Rights of Disabled Persons, Convention against Discrimination in Education, and the Salamanca Statement on Principles, Policy and Practice in Special Needs Education (Meijer \& Watkins, 2019). These documents obligate any country that adopts them to provide socialization for all people, regardless of their health, mental and physical development.

Each country realizes that implementing a state policy for education of people with health limitations should enable an opportunity in high-quality education. Thus, people can acquire an occupation to become equal members of society (Goldman et al., 2017) and determine successful socialization. However, the quality and effectiveness of education for students with health limitations are largely dependent upon their adaptation and integration into a new environment. One of the best ways to improve adaptability of such students is to attract volunteers.

There are two crucial determinants in the work of volunteers: training for helping people with disabilities and emotional closeness, which serves as an important support factor for those with whom the volunteer works. As a rule, volunteers themselves quite effectively evaluate the quality of their training based on the results of their own activities and on the reviews and reactions of the people they help (Rochester et al., 2016; Plotnikov et al., 2019).

The study is devoted to the development, implementation and experimental verification of a program for training volunteers. The effectiveness of program verification is increasing, given that only $23 \%$ of the study participants did not have volunteer experience before, they had the opportunity to evaluate the increase in the effectiveness of their knowledge and skills as a result of completing the program. When assessing the passage of the program using a special questionnaire, participants could rely on their previous experience to compare the results obtained during training. The hypothesis of our study is the assumption that as a result of the training program, volunteers will improve their results and their assessment of their own skills should increase from "low" or "satisfactory" to "high" or "excellent".

A necessary element in creating an inclusive community at universities is the students' active participation in university life, educational process and community building (Goldman et al., 2017). Nowadays, a tendency for higher inclusive education exists even in Russia. Thus, creating a tolerant environment for people with disabilities and organizing volunteer care are becoming crucial. 
The subject of the research is the current level of training of student volunteers in the Far Eastern Region of the Russian Federation, as well as the possibility of increasing both the effectiveness of training and motivation for volunteering. As indicated in studies (Plows \& Whitburn, 2017; Shandra, 2017), the quality of advocacy and support for people with disabilities increases as even theoretical knowledge spreads about the needs and characteristics of such people.

The level of perception and acceptance of them by society increases thanks to literature, films, information about their lives. Accordingly, the implementation of effective training projects will provide an opportunity to both improve the quality of volunteers' work, and will serve to spread this positive impact on society as a whole and can serve to increase the base of the volunteer movement (Yanay-Ventura, 2019).

\section{LITERATURE REVIEW}

These days, much attention is paid to the development of a university student's volunteer movement in the context of inclusive education. The organization and content of volunteer activities in higher education were studied by Russian and foreign researchers (Azarova \& Yanitsky, 2008).

Students' participation in volunteering contributes to building a socially responsible society. Meanwhile, the attention is also given to the development of certain personality traits (Kudrinskaya, 2006), soft skills (Kudrinskaya, 2006; Kiseleva, 2017), axiological attitudes (Kudrinskaya, 2006), socio-psychological readiness (Yada et al., 2018), and professional competencies for future work with disabled people (Kapustina, 2016; Yada et al., 2018).

Volunteering can be considered as a social activity and a resource for inclusive education (Ministry of Education and Science of the Russian Federation, 2014). However, many researchers believe that an inclusive society encourages students with disabilities not only to satisfy basic needs but also to accumulate social resources, providing further progress in society. The inclusion of young people in the "Abilimpix" volunteer movement is aimed at forming significant competencies, as well as supporting the motivation of disabled people, and advancing their career (Sorokin \& Lukovenko, 2018).

Several educationalists suggest including volunteering in the educational process as an informal practice. Thus, volunteering in the higher education system contributes to the formation of students' soft skills, which represent a combination of universal knowledge, personal qualities, and abilities that allow achieving positive results in various areas of life (Buryakova \& Malkova, 2019).

The matter of the youth volunteering potential is focused on two main aspects:

- volunteering impact on the historical situation;

- volunteering influence on a person.

Bogdanovskaya (2016) describes inclusive volunteering as a new technology in social work, promoting healthy lifestyles among modern youth. 
Currently, Russia is summarizing the experience of student volunteering with youth as the main factor of such movement. As a result, the infrastructure and system for organizing cooperation with volunteers have been created. Furthermore, the experience in providing volunteer assistance and inclusion of disabled students in volunteering activity has been accumulated (Rudzynskaya \& Ryabihina, 2017).

Previous findings in the field of inclusive volunteering confirm that students all over the world face the same challenges: interaction with teachers, accompaniment by tutors, stress, and the organization of an accessible environment (Morningstar et al., 2010; Cosier et al., 2013; Li \& Wang, 2013; Darcy et al., 2014; Jeanes et al., 2018). Thus, foreign researchers devote much attention to examine the role of volunteers in the learning process and further involvement of disabled people in the new socio-cultural environment (Mithen et al., 2015; Plows \& Whitburn, 2017; Shandra, 2017; Marková, 2018; Knox et al., 2019). Studies analyzing the benefits of volunteering (personal development, social recognition, and integration) as well as its obstacles (negative attitude, personal considerations, failure to provide social integration to include people with disabilities in volunteering) are of great interest (Rochester et al., 2010; Shandra, 2019; Kappelides \& Spoor, 2018).

Among the studies on the volunteer movement, we were able to find only minor indications of various types of training designed to improve the quality of their training (Morningstar et al., 2010; Lindsay, 2016; Kapustina, 2016). Our study closes this gap and proves the high effectiveness of even relatively short-term training and dissemination of information about helping people with disabilities.

Many works in the volunteering field are conducted to develop a better understanding of volunteer work experience among youth with disabilities. Students with special needs face various challenges, but at the same time, they want to become volunteers, and they can. The results achieved indicate the necessity for a more thorough study of medical and social volunteering aspects (Harvey et al., 2010; Forlin \& Chambers, 2011; Taniguchi \& Thomas, 2011; Hong, 2015; Lindsay, 2016).

Note that these works relate to the discussion and conclusions from the field experience of volunteers and volunteer organizations. They were used to create a training project for this study, but these works themselves practically do not contain a statement of the content or results of the use of training programs for volunteers.

A training program for volunteers was created to develop the skills of accompanying disabled people in higher educational institutions. This program implementation aims to provide the university volunteers with the competencies necessary for the organization of psychological and pedagogical support for disabled students. These competencies include:

- willingness to organize and conduct voluntary activities;

- optimization of interpersonal interaction with disabled students during educational and extracurricular activities (Zyskina \& Romanova, 2011);

- promoting the inclusive culture in higher education (Zyskina \& Romanova, 2011);

- teamwork skills. 
Successful achievement of the goals established became possible owing to the solution of the next problems:

- introducing the legislative and regulatory framework to govern the implementation of charitable and volunteer activities;

- identifying self-reported perceptions of future volunteers towards problems that students with special needs face during the university study;

- providing a better understanding of students with special needs as a specific group (behavior, features of their cognitive and emotional-volitional spheres);

- outlining possible difficulties in communication with disabled students and ways to overcome them;

- analyzing and summarizing the experience in interacting with students with limitations under various conditions.

Particular emphasis was placed on the development of such personal volunteers' qualities as humanity, mercy, involvement, diligence, tolerance, active life position, empathy.

A methodology for studying future volunteers' self-report on perceptions towards persons with various disabilities and difficulties during the formation of accompanying skills is created.

The objective of the study is to test the effectiveness of the training project proposed by the authors to improve the quality of training volunteers. Given the small number of this type of research and the wide geographical scope of the study, it can be of great value in expanding the volunteer movement and attracting students to support people with disabilities.

The research is aimed at:

- revealing the information about students with special needs by surveying on a 5-point scale;

- determining the readiness of future volunteers to accompany students with disabilities in educational and extracurricular activities by surveying before training and evaluation are conducted.

\section{METHOD}

\section{Research design and sample}

For the study, a quantitative research method was chosen based on a survey using a special questionnaire. This method was chosen in order to determine the various parameters of the change in the quality of self-assessment and training of volunteers according to their preliminary experience and as a result of the training project.

In 2019, according to the program for developing skills in accompanying people with disabilities in higher educational institutions, volunteers among students and workers of 8 universities in the Far Eastern Federal District (FEFD) were trained:

- Khabarovsk Krai (Khabarovsk State University of Economics and Law (KSUEL); Pacific National University (PNU), Far Eastern State Academy of Physical Culture (DVGAFK), Amur State University of Humanities and Pedagogy (AmSGPU));

- Primorsky Krai (Vladivostok State University of Economics and Service (VSUES)); 
- Amur Oblast (Annunciation State Pedagogical University (BSPU));

- Kamchatka Krai (Kamchatka State University named after Vitus Bering (KamGU named after Vitus Bering));

- Magadan Oblast (North-East State University).

From October 22 to November 28, 2019, 75 students and 3 workers from 8 universities of the FEFD, were trained under the program for developing skills in accompanying persons with disabilities:

- Khabarovsk Krai (KSUEL - 12, PNU - 6, DVGAFK - 3 (Khabarovsk), AmSGPU 21 (Komsomolsk-on-Amur)) - 43 participants;

- Primorsky Krai (VSUES) - 3 participants;

- Amur Oblast (BSPU) - 20 participants;

- Kamchatka Krai (KamGU named after Vitus Bering) - 2 participants;

- Magadan Oblast (Nizhny Novgorod State University) - 10 participants.

In order to study the proposed training program, representatives of all regions of the Far Eastern Federal Region of Russia were invited with the aim of the widest possible geographical representation of the participants. Participants were selected based on the results of research and selection among those who actively participated in the public and special volunteer programs described below. Also, in order to attract those who did not have previous experience of volunteering in universities, messages were sent about the possibility of joining this program for those who wanted.

Of the survey participants, $40 \%$ had experience in volunteering in the medicalpedagogical centers, volunteer coordination centers, volunteer festivals, forums "Who, if not me?", and "Victory Volunteers", in the "Miriada" volunteer unit, volunteering in orphanages, and with disabled children. Other $37 \%$ reported on one-time participation, and only $23 \%$ of the participants had no experience in volunteering at all. About $35 \%$ of people in the survey had an experience of interaction with disabled persons, $10 \%$ reported on one-time interaction, and $55 \%$ indicated the absence of any cooperation (Figure 1).

Experience in volunteering and interaction with disabled

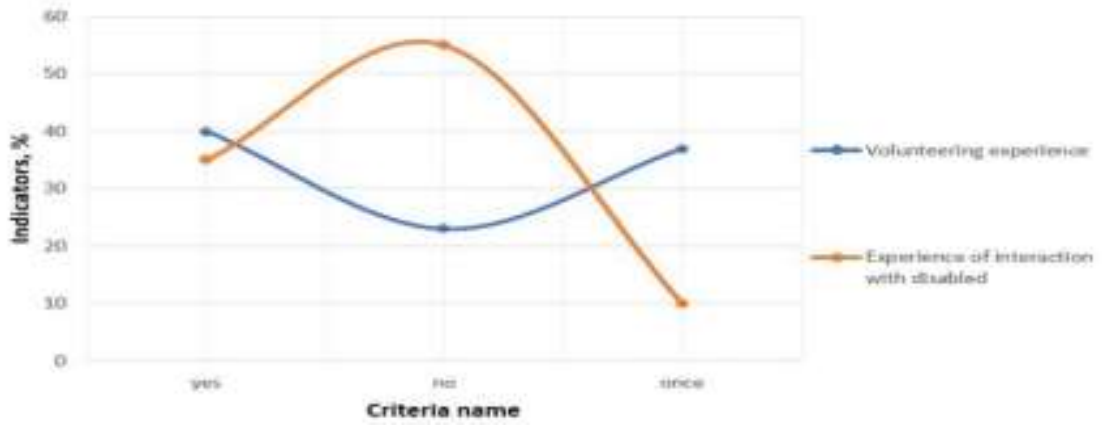

Figure 1

Experience in volunteering and interacting with disabled 
The training program passed by inviting participants to participate in training sessions at the Khabarovsk State University of Economics and Law for two weeks. At the end of the course, participants were offered a questionnaire to assess changes in skills, attitudes towards volunteer work and other training factors. Considering that $76 \%$ of the program participants had the experience of accompanying people with disabilities of various types, as well as the presence of practical exercises in the program, participants had the opportunity to effectively evaluate the quality of the program and the change in their capabilities and skills (Rochester et al., 2016; Plotnikov et al., 2019). Researchers consider a particularly important part of the assessment to be a change in attitudes toward people with disabilities, as well as increased assessments of volunteer work and increased motivation.

No personal data of the study participants were recorded or stored, participation in the program and study was exclusively voluntary, and all training participants were not familiar with each other before this study.

\section{Statistical processing}

To conduct the current study, a questionnaire method, Student's t-test and Chi-square test were used. An analysis of arbitrary contingency tables was applied to determine the statistical significance of training activities with a $\chi^{2}$ criterion (chi-square). The $\chi^{2}$ criterion is a nonparametric analogy of variance analysis for comparing several groups according to a qualitative character:

- number of degrees of freedom $=16$;

- value of the $\chi 2$ criterion is 60.373 ;

-critical value of $\chi 2$ at a significance level of $p=0.01$ is 32 ;

-relation between the factorial and effective features is statistically significant at a significance level of less than 0.01 .

To determine the effectiveness of training activities, a statistical data analysis is performed using the Student t-test for dependent samples. Coefficient $(\mathrm{t})<0.05$ (error up to $5 \%$ ) demonstrates that the measures for volunteers' self-report on perceptions have changed after the training process.

\section{Research limitations}

Current research is based on limited data. A relatively small percentage of the total number of students participating in the study was covered. Since the participants' sampling process required the presence of interest in volunteering, most of the students had that experience. Consequently, a survey on the self-assessment level may partially correlate with the psychological readiness of volunteers to improve their skills. The objective evaluation of the acquired knowledge and the experience of its application was not conducted. These issues are reserved for future work in this area.

\section{FINDINGS}

The self-report perceptions of people with various disabilities and rules for interacting with them before the training events were identified on the 5-point scale. According to the results obtained, students mainly had an average self-reported perception towards 
persons with visual impairment, hearing, motor, speech, and debilitating diseases (including blood disorders, endocrine system, circulatory system, respiratory, digestive, skin and subcutaneous tissue, musculoskeletal system and connective tissue, genitourinary system). According data are summarized in Table 1.

Table 1

Self-report on perceptions toward disabled before training

\begin{tabular}{lllllll}
\hline \multirow{2}{*}{ No. } & Disorder & \multicolumn{2}{l}{ Perception assessment, $\%$} & & \\
\cline { 3 - 7 } & & low & below average & average & above average & high \\
\hline 1 & Visual & 8 & 10 & 34 & 24 & 24 \\
\hline 2 & Hearing & 6 & 12 & 32 & 24 & 23 \\
\hline 3 & Motor & 10 & 5 & 28.3 & 28.3 & 28.3 \\
\hline 4 & Speech & 6 & 6 & 31 & 31 & 23 \\
\hline 5 & Debilitating diseases & 12 & 12 & 30 & 23 & 23
\end{tabular}

When the respondents were asked to evaluate the level of volunteers' perceptions toward the problems of accompanying persons with special needs, the individual peculiarities of such people, and volunteering itself, the surveyed indicated rather low or satisfactory evaluation level. The results are described in Table 2.

Table 2

Evaluation of volunteers' perceptions before training

\begin{tabular}{llllll}
\hline \multirow{2}{*}{ No. } & Perception towards... & \multicolumn{2}{l}{ Perception assessment, $\%$} & excellent \\
\cline { 3 - 6 } & & low & satisfactory & good & 16 \\
\hline 1 & accompaniment problems & 44 & 34 & 8 & 6 \\
\hline 2 & individual peculiarities & 56 & 32 & 10 & 5 \\
\hline 3 & volunteering & 48 & 38 & 4 \\
\hline
\end{tabular}

Thus, the results displayed in Table 2 confirm the necessity for volunteers' training and the formation of professional competencies to accompany students with disabilities.

The current research consists of two parts. The first part introduces the theoretical examination of regulatory support of volunteering in the Russian Federation. The main groups of students with disabilities and individual peculiarities receiving higher education at universities in Russia are also described. The peculiarities of psychophysical development (cognitive, emotional, and volitional processes), intracollective and interpersonal relations of students with limitations are examined (Kholina, 2011).

The second, practical part of the research includes incorporating skills that allow helping learners with visual, hearing, musculoskeletal (MSDs), and somatic symptom disorders (SSDs). In the Regional Resource and Education Center for Disabled People and People with Special Needs students were trained to work with special technical teaching aids. The program included induction training in the Russian manual alphabet, sign language, and Braille writing. Future volunteers were involved in the organization and implementation of activities for the socialization, adaptation, rehabilitation, and integration of students with special needs in the educational environment of the university. During the learning process, a training "How to help society understand people with limited physical abilities" was held. It became remarkably useful for 
volunteers since students had to perform three basic sets of exercises: to imagine oneself as a person with hearing, visual, and musculoskeletal disorder.

As a result, students showed more or less interest in various types of volunteer activities. Relevant data are presented in Table 3. In general, the level of interest was above average on the following criteria:

- assistance in everyday tasks;

- learning assistance;

- psychological support;

- support in socio-cultural adaptation;

- fundraising.

Table 3

Interest in various types of volunteering

\begin{tabular}{lllllll}
\hline \multirow{2}{*}{ No. } & Activity type & \multicolumn{7}{l}{ Interest assessment, \% } & \\
\cline { 3 - 7 } & & low & below average & average & above average & high \\
\hline 1 & Assistance in everyday tasks & 4 & 9 & 26 & 33 & 28 \\
\hline 2 & Learning assistance & 3 & 4 & 31 & 42 & 20 \\
\hline 3 & Psychological support; & 1 & 1 & 21 & 30 & 47 \\
\hline 4 & Support in socio-cultural adaptation; & 3 & 3 & 12 & 38 & 44 \\
\hline 5 & Fundraising & 15 & 17 & 30 & 23 & 15 \\
\hline
\end{tabular}

Future volunteers were asked to evaluate training activities on a 5-point scale, where 1 corresponds to the minimum rating, and 5 corresponds to the maximum, according to:

- novelty;

- practical value;

- atmosphere;

- handout materials;

- organization of training process.

The majority (96\%) of respondents highly evaluated training activities, noting the novelty $(83 \%)$, the practical value of the material $(94 \%)$, the atmosphere $(98 \%)$, the presence of handout materials $(98 \%)$, and excellent organization of training process (99\%). Related data are presented in Figure 2.

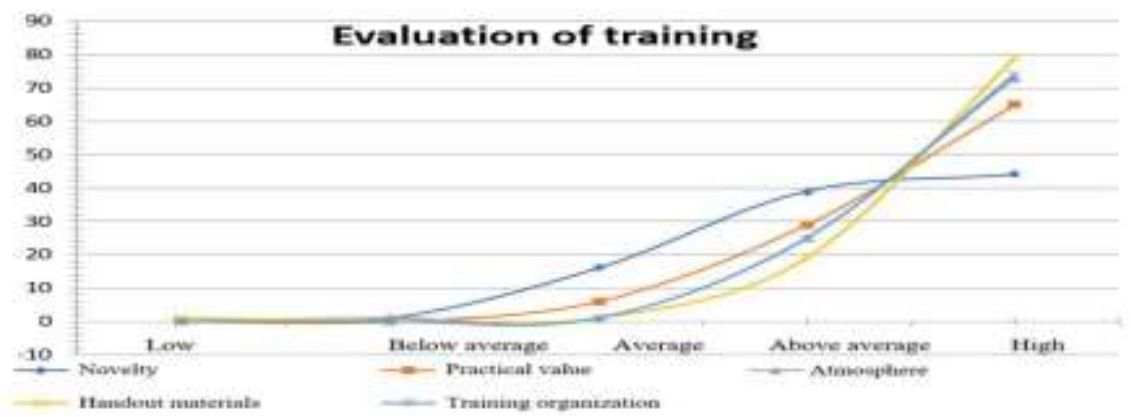

Figure 2

Evaluation of volunteers' training 
Among the proposed subjects for the study the following ones were of particular interest: "General characteristics of the problems faced by students with disabilities at the university" (33\%), "Psychological and pedagogical characteristics of students with disabilities (according to various nosologies)" (22\%), "Possible participation of volunteers in the organization and implementation of accompanying students with disabilities at the university" (29\%), "Regulatory support of volunteer activities" (6\%).

To attract attention to the problems of university students with various disabilities, volunteers prefer joint creative work (33\%), meetings to familiarize and organize activities $(23 \%)$, educational events (19\%), charity events (16\%), information sharing through social networks $(9 \%)$.

The most prominent interest and desire for a thorough study among students were provoked by:

- psychological and pedagogical characteristics of persons with disabilities;

- practical training.

Self-reports on perceptions toward individual peculiarities of people with disabilities and the rules for interacting with them were reviewed to determine the effectiveness of training. The results reveal that before the training activities, students' average level of perceptions increased to "above average" and "high". The "low" evaluation is not observed. The relevant information is generalized and presented in Figure 3.

Perceptions' assessment

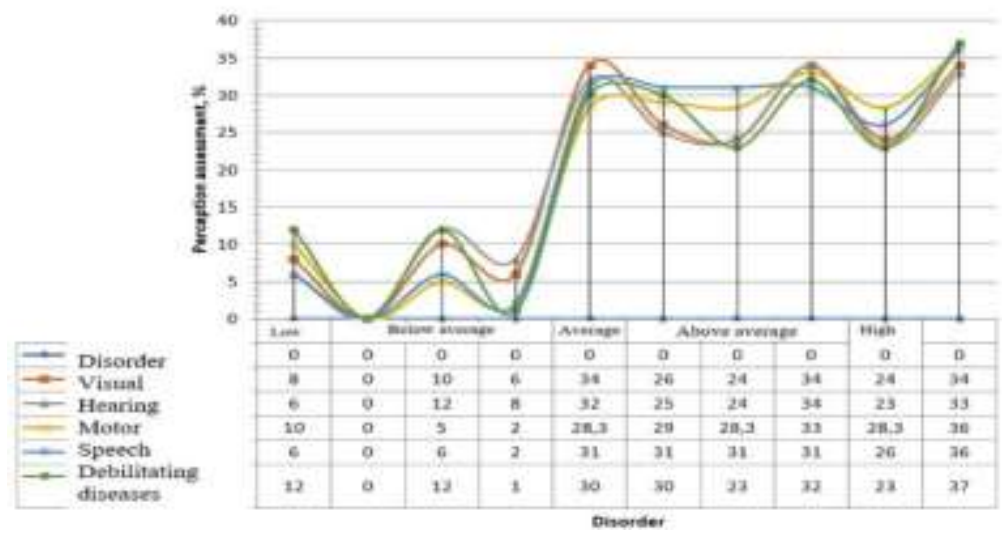

Figure 3

Perceptions' assessment before and after training

To determine the effectiveness of training activities, a statistical data analysis is performed using the Student t-test for dependent samples. Coefficient $(\mathrm{t})<0.05$ (error up to $5 \%$ ) demonstrates that the measures of self-report on volunteers' perceptions have changed after the training process or remain the same. It provides high chances for the results to be analyzed thoroughly (Table 4 ). 
Table 4

Self-report on volunteers' perceptions based on the Student's t-test calculation

\begin{tabular}{lllllll}
\hline \multirow{2}{*}{ No. } & T-test type & \multicolumn{4}{l}{ Perception assessment } \\
\cline { 3 - 6 } & & low & below average & average & above average & high \\
\hline 1 & Student's t-test & 0.0009 & 0.0119 & 0.1039 & 0.0129 & 0.0003 \\
\hline
\end{tabular}

Hence, low and high self-report measures (0.0009 and 0.0003) show that the training is planned and carried out effectively. Measures "below average" and "above average" have changed insignificantly (0.0119 and 0.0129). The "average" perception remains the same (0.1039). Nevertheless, this proves the need to review some aspects of the volunteer training program or a more thorough selection of students willing to become volunteers.

When participants were proposed to evaluate the changes in the level of volunteers' perceptions about the problems of accompanying persons with various disabilities, about individual peculiarities of such people, and volunteering itself, volunteer students noted significant changes (48\%) and more comprehensive knowledge (51\%). Corresponding results are presented in Figure 4 and Table 5.

\section{Volunteers' perceptions before and after training}

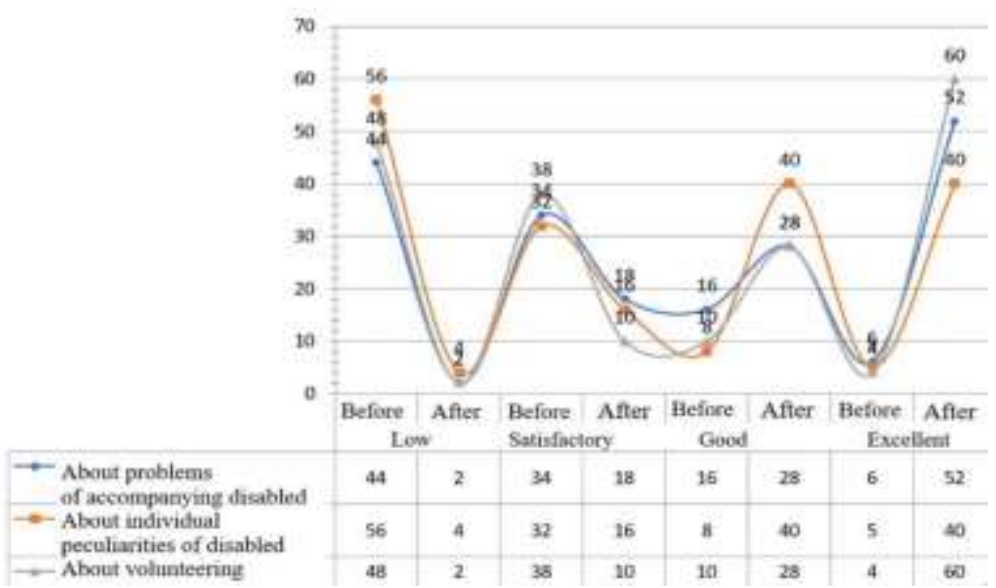

Figure 4

Volunteers' perceptions before and after training

Table 5

Perceptions' evaluation based on the Student's t-test calculation

\begin{tabular}{llllll}
\hline No & T-test type & \multicolumn{3}{l}{ Perceptions assessment } & \begin{tabular}{l} 
changed \\
\cline { 3 - 6 }
\end{tabular} \\
\cline { 3 - 6 } & $\begin{array}{l}\text { remain } \\
\text { the same } \\
\text { (low) }\end{array}$ & $\begin{array}{l}\text { changed } \\
\text { insignificantly } \\
\text { (satisfactory) }\end{array}$ & $\begin{array}{l}\text { significantly } \\
\text { (good) }\end{array}$ & $\begin{array}{l}\text { became } \\
\text { comprehensive } \\
\text { (excellent) }\end{array}$ \\
\hline 1 & Student's t-test & 0.0019 & 0.0188 & 0.0366 & 0.0085 \\
\hline
\end{tabular}

Thus, the statistical data based on the calculation of Student's t-test enable affirming the training effectiveness. 
In response to the question "What has changed in your life after participating in a training project?" the participants replied that they realized the importance of volunteering to accompany people with disabilities. Moreover, the respondents admitted the increased interest and motivation in working with disabled people. Furthermore, volunteers reported on the formation of a different attitude towards persons with special needs. The majority of participants felt as if they became more attentive to such people and more knowledgeable in matters of accompanying the disabled. Furthermore, volunteer students confessed that they understood the increasing importance of the problems of persons with limitations and want to pay more attention to these issues. Besides, a different attitude towards people with disabilities is already noticeable among the participants of the survey. To further research, students recommend expanding the geography of this project.

Moreover, the improvement in the understanding of how to interact with disabled people is also noted. The volunteers' self-report on perceptions towards the problems of accompanying disabled persons, the individual peculiarities of such people, and volunteering itself after training has increased from "low" and "satisfactory" to "good" and "excellent". It is confirmed by the Student's t-test calculations. Based on this, it can be argued that the hypothesis of the study was confirmed.

\section{DISCUSSION}

A growing body of literature has examined the volunteer movement. In recent years, theoretical and practical studies in the use of volunteers to accompany people with disabilities appear more often (Rochester et al., 2016; Kaveh et al., 2017; Plotnikov et al., 2019; Yanay-Ventura, 2019). The widespread use of inclusion principles in European and American educational institutions allows accumulating significant comparative material. Besides, the examination of problems arising in the process of more extensive involvement of people with disabilities or special needs in social interaction became possible (Rochester et al., 2016; Yada et al., 2018; Meijer \& Watkins, 2019). The research data are insignificantly related to the issue of support and advocacy of people with disabilities and social initiatives that perform this function. Our research focuses on this very aspect of the problem.

The practice of exclusion in all areas of public and professional life, based on the mentioned international documents, provides many opportunities to live a full life. People with special needs have a chance to serve in the army, they can get any specialized profession, and participate in social life without hindrance or limitations. Moreover, a practice of attracting people with disabilities for volunteering shows excellent results (Shandra, 2017; Yanay-Ventura, 2019; Shandra, 2019). This method is especially important because it increases the self-assessment of persons with various disabilities and improves their accompaniment. As shown in our study, attracting people with disabilities for volunteering, like training projects, increases the number of volunteers and their motivation. The reason for this is that people with special needs have a much better understanding of the real needs of other persons with certain functional limitations. 
Applying students with functional disabilities as volunteers to help their fellows is a common practice in Western higher education institutions and often becomes an object for various research (Cosier et al., 2013; Hong, 2015; Gorlova et al., 2016). In Russia, this experience is hardly ever used, however, during the training described in the article, volunteers introduced this approach and described its effectiveness.

The history of the application of international law concerning the protection of rights and adaptation in the society of people with disabilities is also studied in many sources (Harvey et al., 2010; Meijer \& Watkins, 2019). In order for volunteers to feel confident when accompanying people with disabilities, as experience shows, a clear understanding of the laws that ensure the rights of these people is necessary. One of the important functions of volunteers for which they should be prepared is to protect disabled pupil from bullying or neglect by their relatives (Adegboyega, Okesina \& Jacob, 2017). Due to the widespread use of e-learning, as well as non-lecture types of knowledge acquisition, web-based volunteer training programs for "advocating for individuals with disabilities" are of great importance (Goldman et al., 2017). In the process of web training, it is possible to attract more volunteers than in student communities through social networks, e-learning at universities, and free courses. A good experience in tracking the performance of people with disabilities at the secondary level in the study Kangas \& Cook, (2020) can be successfully applied to university students. Studies show that people with specific learning disabilities can have good results when using special teaching methods and with support (Ikhwanudin \& Suryadi, 2018). This is also confirmed by our research: those who had volunteering experience or theoretical knowledge earlier had better results. Therefore, we consider the training of student volunteers so important that provide support to those people with disabilities who are seeking education. The authors are inclined to the idea that the presence of motivated and qualified support for their environment is a critical factor in ensuring the academic performance of people with disabilities. (Orakci, Aktan, Toraman \& Çevik, 2016). The role of teacher training in inclusive educational practice, studied in this work, is very high, but in academic education the role of volunteers among the students themselves can be even more important. However, confirmation of this assumption requires further investigation.

Among a certain number of people, only a part of them will be ready to become a volunteer and undergo specialized training. This study examines only the student environment, while Western researchers prefer to involve more extensive networks of social support for persons with disabilities. Western scholars use social networking and web-oriented projects that can be developed on university organizations to provide the necessary knowledge and training (Goldman et al., 2017; Plows \& Whitburn, 2017).

Sport is one of the most effective forms of restoring social status and activating people with disabilities, who are unsure of themselves or unable to fulfill their potential. This usually requires the help of social workers, sports volunteers and coaches, which was also part of our training project. For instance, the Deaflympics, the Paralympic Games, etc. (Li \& Wang, 2013; Darcy et al., 2014). A significant number of participants in such sports are university students. Many scholars indicate the importance of sporting events 
for the rehabilitation and "advocacy" of people with disabilities. Physical activity can help to demonstrate to oneself and society the absence of real or imaginary impairment in behavior or opportunities (Kappelides \& Spoor, 2018; Cosier et al., 2013). Our study also found that it is the perception of people with disabilities that is often a big problem for volunteers. An increasing number of studies confirm that attracting people with disabilities at a young age is especially important because during this period life stereotypes are changing easier (Morningstar et al., 2010; Cosier et al., 2013; Jeanes et al., 2018).

This research also reveals that after training the motivation for the volunteers' interaction with disabled people increases along with behaviour confidence. The results achieved have a number of similarities with Goldman et al. (2017) findings, in particular, in the case of training through the Internet.

\section{CONCLUSION}

Our research confirms the possibility and necessity of significantly increasing both the motivation and the confidence of volunteers through relatively short training programs. The novelty of the study lies in the fact that the training project was studied with a wide sample of volunteers covering the largest geographic regions. This will significantly increase the influx of volunteers and improve the quality and volume of assistance to people with disabilities.

An independent assessment of the results of the course showed that $48 \%$ of volunteer students noted significant changes in the level of perceptions about the problems of accompanying persons with various disabilities and about individual peculiarities of such people and $51 \%$ of students indicated that they had gained more comprehensive knowledge. $96 \%$ of respondents highly evaluated training activities, noting the novelty $83 \%$ noted the novelty of training, $94 \%$ pointed out the high practical value of the training materials, which they could evaluate from their past experience, $98 \%$ appreciated the quality of the training atmosphere as "high", 98\% pointed out the usefulness of the handout materials, $99 \%$ pointed excellent organization of training process (fig. 2).

The level of assessment of skills in the "excellent" group has changed in relation to solving the problems of accompanying disabled from $6 \%$ to $52 \%$ in the group. With regard to understanding individual peculiarities and needs of disabled - from $5 \%$ to $50 \%$. The assessment of volunteering as a form of employment as "excellent" has changed from $4 \%$ to $60 \%$. The last factor also indicates that the program can effectively cope with the task of attracting new volunteers and increasing the motivation and quality of work of volunteers. The number of respondents who rated their level of training as "low" in various forms of volunteering from $44-56 \%$ in different types decreased after passing the program to $2-4 \%$, respectively (fig. 4).

Volunteering remains a wide range of social activities aimed at providing a variety of assistance to people who need support and accompaniment. Volunteer activities include traditional forms of mutual support, official services, and other forms of civic participation, performed voluntarily to benefit another person, group, or organization. 
According to the surveys (Tables 1 and 2), several problems in attracting volunteers exist:

- future volunteers do not have a clear idea of which attitude towards disabled persons is correct. Many volunteers willing to assist students with disabilities find it hard to establish contacts because of internal insecurity and fear;

- volunteers' knowledge about the problems of students with special needs is extremely insufficient. Volunteers do not have information about methods and technologies for supporting this category of students applied in Russia and abroad;

- most of the volunteers have no experience in interacting and helping people with disabilities in various situations. Lack of personal experience as well as communication with this category of students cause psycho-emotional stress in response to the interaction with disabled.

Concerning the relevant results of the study, one can argue that the developed training program is effective and can be used as a basis for similar specialized trainings.

After the volunteers' feedback analysis, the following recommendations were summarized for future research.

1. Continue the current volunteer training in 2020 while focusing on practice, i.e., the arrangement of forums, meetings, and various training activities.

2. Organize a volunteer movement for the Far Eastern Federal District in support of professional orientation, employment, and university study for people with limitations.

The results of the current research will be used to improve volunteer training programs.

\section{REFERENCES}

Adegboyega, L. O., Okesina, F. A., \& Jacob, O. A. (2017). Family Relationship and Bullying Behaviour among Students with Disabilities in Ogbomoso, Nigeria. International Journal of Instruction, 10(3), 241-256.

Azarova, E. S., \& Yanitsky, M. S. (2008). Psychological determinants of volunteering. Tomsk State University Journal, 306, 120-126.

Bogdanovskaya, V. I. (2016). About inclusive volunteering as the resource on formation of culture of the healthy lifestyle. In S. T. Cohan (Ed.), Health status: medical, social, psychological and pedagogical aspects: collection of articles (pp. 573583). $\quad$ Retrieved $27 \quad$ December, 2019 from http://zabgu.ru/files/html_document/pdf_files/fixed/Ob_inklyuzivnom_dobrovol\%27che stve/Bogdanovskaya_V.I._Ob_inklyuzivnom_dobrovolchestve....pdf

Buryakova, K. I., \& Malkova, I. Yu. (2019). Opportunities and problems of key competences development of youth in volunteer activities at non-profit organization. Siberian Pedagogical Journal, 1, 7-13. 
Cosier, M., Causton-Theoharis, J., \& Theoharis, G. (2013). Does access matter? Time in general education and achievement for students with disabilities. Remedial and Special Education, 34(6), 323-332.

Darcy, S., Dickson, T. J., \& Benson, A. M. (2014). London 2012 Olympic and Paralympic Games: Including volunteers with disabilities: A podium performance? Event Management, 18(4), 431-446.

Forlin, C., \& Chambers, D. (2011). Teacher preparation for inclusive education: Increasing knowledge but raising concerns. Asia-Pacific Journal of Teacher Education, 39(1), 17-32.

Goldman, S. E., Burke, M. M., Mason, C. Q., \& Hodapp, R. M. (2017). Correlates of sustained volunteering: Advocacy for students with disabilities. Exceptionality, 25(1), 40-53.

Gorlova, N. I., Troska, Z. A., Gureeva, E. A., \& Krutitskaya, Y. V. (2016). The practice of teaching volunteers with skills of deaf communication to participate in the XVIII Deaflympics winter games: Research and results. Indian Journal of Science and Technology, 9(48), 0974.

Harvey, M. W., Yssel, N., Bauserman, A. D., \& Merbler, J. B. (2010). Preservice teacher preparation for inclusion: An exploration of higher education teacher-training institutions. Remedial and Special Education, 31(1), 24-33.

Hong, B. S. S. (2015). Qualitative analysis of the barriers college students with disabilities experience in higher education. Journal of College Student Development, 56(3), 209-226.

Ikhwanudin, T., \& Suryadi, D. (2018). How Students with Mathematics Learning Disabilities Understands Fraction: A Case from the Indonesian Inclusive School. International Journal of Instruction, 11(3), 309-326.

Jeanes, R., Spaaij, R., Magee, J., Farquharson, K., Gorman, S., \& Lusher, D. (2018). 'Yes we are inclusive': Examining provision for young people with disabilities in community sport clubs. Sport Management Review, 21(1), 38-50.

Kangas, S. E., \& Cook, M. (2020). Academic Tracking of English Learners With Disabilities in Middle School. American Educational Research Journal, 0002831220915702.

Kappelides, P., \& Spoor, J. (2018). Managing sport volunteers with a disability: Human resource management implications. Sport Management Review, 22(5), 694-707.

Kapustina, A. N. (2016). Volunteer activities as a self-actualization resource. Universum: Psychology and Education, 3-4(22), 1-12.

Kaveh, M. H., Rokhbin, M., Mani, A., \& Maghsoudi, A. (2017). The role of health volunteers in training women regarding coping strategies using self-efficacy theory: 
barriers and challenges faced by health volunteers in empowerment of women. Asian Pacific Journal of Cancer Prevention, 18(9), 2419-2424.

Kholina, O. I. (2011). Volunteering as a social phenomenon of modern Russian society. Theory and Practice of Social Development, 8, 71-73.

Kiseleva, I. N. (2017). The use of innovative approaches to the organization of volunteering in universities in modern Russia. Modern High Technologies, 8, 105-110.

Knox, J., Wang, Y., \& Gallagher, M. (2019). Artificial Intelligence and Inclusive Education. Speculative Futures and Emerging Practices. Singapore: Springer.

Kudrinskaya, L. A. (2006). Volunteer work: the experience of theoretical reconstruction. Moscow: Publishing house of Moscow University.

Li, C., \& Wang, C. K. J. (2013). Effect of exposure to special Olympic games on attitudes of volunteers towards inclusion of people with intellectual disabilities. Journal of Applied Research in Intellectual Disabilities, 26(6), 515-521.

Lindsay, S. (2016). A scoping review of the experiences, benefits, and challenges involved in volunteer work among youth and young adults with a disability. Disability and Rehabilitation, 38(16), 1533-1546.

Marková, A. (2018). The 'inclusive volunteering' phenomenon: Research into the volunteering of people with disabilities. Kontakt, 20(1), 48-56.

Meijer, C. J., \& Watkins, A. (2019). Financing special needs and inclusive educationfrom Salamanca to the present. International Journal of Inclusive Education, 23(7-8), 705-721.

Ministry of Education and Science of the Russian Federation (2014). Methodological recommendations about Management of Educational Process for Training of Disabled People and Individuals with Disabilities in the Higher Educational Institutions including Equipment of Educational Process" of April 08, 2014 AK-44/05vn. Retrieves 27 December, 2019 from http://base.garant.ru/70680520/

Mithen, J., Aitken, Z., Ziersch, A., \& Kavanagh, A. M. (2015). Inequalities in social capital and health between people with and without disabilities. Social Science \& Medicine, 126, 26-35.

Morningstar, M. E., Frey, B. B., Noonan, P. M., Ng, J., Clavenna-Deane, B., Graves, P., Kellems, R., McCall, Z., Pearson, M., Wade, D. B., \& Williams-Diehm, K. (2010). A preliminary investigation of the relationship of transition preparation and selfdetermination for students with disabilities in postsecondary educational settings. Career Development for Exceptional Individuals, 33(2), 80-94.

Orakci, S., Aktan, O., Toraman, Ç., \& Çevik, H. (2016). The Influence of Gender and Special Education Training on Attitudes Towards Inclusion. International Journal of Instruction, 9(2), 107-122. 
Plotnikov, A. V., Kovalenko, K. E., Prodanova, N. A., Noeva, E. E., Astapenko, E. O., \& Aleks, Y. (2019). Social entrepreneurship of persons with disabilities. Journal of Entrepreneurship Education, 22(2), 1-9.

Plows, V., \& Whitburn, B. (2017). Inclusive Education. Making Sense of Everyday Practice. Sense Publishers.

Rochester, C., Paine, A. E., Howlett, S., \& Zimmeck, M. (2010). Making Volunteering Inclusive. In: Volunteering and Society in the 21st Century. London: Palgrave Macmillan.

Rochester, C., Paine, A. E., Howlett, S., Zimmeck, M., \& Paine, A. E. (2016). Volunteering and Society in the 21st Century. Singapore: Springer.

Rudzynskaya, T. F., \& Ryabihina, A. V. (2017). The inclusion of young people in volunteer movement "Abilimpix" as a condition for the formation of an inclusive society. Kazan Bulletin of Young Scientists, Historical Sciences, 1(3), 120-124.

Shandra, C. L. (2017). Disability and social participation: The case of formal and informal volunteering. Social Science Research, 68, 195-213.

Shandra, C. L. (2019). Disability Segregation in Volunteer Work. Sociological Perspectives, 63(1), 112-134.

Sorokin, N. Y., \& Lukovenko, T. G. (2018). Readiness for training disabled students in academic staff of universities. Psychological Science and Education, 23(2), 68-76.

Taniguchi, H., \& Thomas, L. D. (2011). The Influences of religious attitudes on volunteering. Voluntas, 22, 335-355.

Yada, A., Tolvanen, A., \& Savolainen, H. (2018). Teachers' attitudes and self-efficacy on implementing inclusive education in Japan and Finland: A comparative study using multi-group structural equation modelling. Teaching and Teacher Education, 75, 343355.

Yanay-Ventura, G. (2019). "Nothing about us without us" in volunteerism too: Volunteering among people with disabilities. VOLUNTAS: International Journal of Voluntary and Nonprofit Organizations, 30(1), 147-163.

Zyskina, M. A., \& Romanova, E. A. (2011). Training of volunteers for work with disabled people. Ekaterinburg: UMTs UPI Publishing House. 